\title{
A Propósito de la Cirugía Bucal...
}

\author{
Apropos of Oral Surgery...
}

\author{
Karla Moscoso*
}

Moscoso, K. A propósito de la cirugía bucal... Int. J. Odontostomat., 10(1):5-6, 2016.

Desde hace unas semanas se discute, el hecho ya consumado, de la incorporación de la cirugía bucal como especialidad. El asunto ha convocado, como pocas veces, el interés de la comunidad odontológica, pues parecieran existir pocos argumentos de peso para su creación, y ha puesto en pie de guerra a los maxilofaciales. Pero ¿quién tiene la razón? A mi juicio, el problema de la cirugía bucal no es más que un síntoma de una enfermedad, mal diagnosticada por la Comunidad Odontológica y peor tratada por el Ministerio de Salud.

La Sociedad de Cirugía Máxilofacial argumenta que existe un número suficiente de profesionales formados o en formación para dar respuesta a la problemática de salud. Los residentes que no tiene retorno (por ejemplo los EDF) se muestran deseosos de integrarse al sector público, pero no existen cargos hospitalarios para ellos. Desde ese prisma, pareciera ser más un tema gremial que sanitario. Sin embargo llevan la razón en algo: la infraestructura disponible para acciones quirúrgicas No GES no tiene prioridad en la asignación de pabellones, y los odontólogos, en muchos casos, deben solicitar con insistencia espacios quirúrgicos.

Por otro lado, el MINSAL argumenta que existen largas listas de espera para cirugía odontológica, donde lo predominante son las extracciones de terceros molares, complicaciones de exodoncias y otras patologías de resolución en sala de procedimiento. En estricto rigor, las actividades de cirugía bucal son lo más frecuente de estas listas de espera versus una menor cantidad de actividades quirúrgicas de mayor complejidad, correspondientes al perfil profesional de un maxilofacial. De hecho, las cirugías de exclusiva resolución de parte del cirujano maxilofacial en un hospital de alta complejidad, son sólo $12,34 \%$ del total de acciones odontológico quirúrgicas (Moscoso \& Smok, 2015).

¿Que creo yo? Que el origen de este síntoma de enfermedad, correspondiente a la creación de nuevas especialidades, se remonta a muchos años atrás, cuando se da inicio a la formación de los odontólogos.

Si se observan las estadísticas del Servicio Médico Legal, principal institución encargada de ejecutar pericias de responsabilidad sanitaria, se aprecia que los odontólogos corresponden a la $5^{a}$ especialidad más demandada y, del total de casos periciados, el $24 \%$ corresponde a complicaciones quirúrgicas y $21 \%$ a complicaciones infecciosas (Salinas, 2012). Paralelamente, según las cifras de mediación de la Superintendencia de Salud, los casos odontológicos corresponden al 7,6 $\%$ del total de casos ingresados, correspondiente a la tercera especialidad más demandada (Superintendencia de Salud, 2015). En contraste, en el área pública (Consejo de Defensa del Estado, 2015), donde la odontología está escasamente representada, las pericias odontológicas son 1,9\% del total de mediaciones. Sin embargo, el $11 \%$ de ellas corresponden a causas quirúrgicas y el $5 \%$ a maxilofacial. En forma paralela se observa que los odontólogos fallan más que los médicos: $35 \%$ de los casos odontológicos en peritaje médico legal poseen infracción a la lex artis versus solo el 9 $\%$ de los casos médicos.

Con estos antecedentes, resulta imperativo preguntarse qué está pasando con las competencias de los odontólogos que se están formando. A riesgo de crear polémica, pienso que la enfermedad se llama "síndrome de formación de profesionales de mala calidad", cuyos síntomas son: 
- La creación de nuevas especialidades que vienen a resolver la baja preparación que tienen muchos colegas (así la cirugía bucal sería una solución provisoria para remediar las bajas competencias en el área).

- Un escaso conocimiento de bioética, lo que dificulta a los profesionales objetivar sus competencias y los expone a denuncias por impericia, imprudencia o negligencia.

- Perpetuo uso de un modelo donde el odontólogo es el centro de su mundo, desconectado de la visión de un ser humano como un todo, y con escasas habilidades para relacionarse con el equipo de salud.

El efecto final de esta situación, es la subvaloración de las patologías dentales, lo que eterniza entre los pacientes y otros profesionales sanitarios, el paradigma de "nadie se muere de caries" y entre los colegas, la "boca aguanta todo".

La comunidad odontológica ha sido lenta en diagnosticar y tratar esta enfermedad. Lamentablemente, el Colegio de Dentistas pareciera no tenerla entre sus prioridades y las universidades, uno de los principales factores que contribuyen a la propagación, no dan señales de adaptar los perfiles y competencias de los futuros odontólogos a los problemas de salud oral que tiene el país.

No obstante y por los factores que sea, económicos, obstinación o simple desidia, la lentitud con que todos los involucrados se adaptan a esta patología solo ha contribuido a agravar los síntomas, y urge tomar medidas, porque en salud oral siempre ha sido mejor prevenir que curar.

\section{AGRADECIMIENTOS}

Al Dr. Franco Sandretti y Dr. Marco CornejoOvalle, quienes colaboraron desinteresadamente en la corrección de este texto.

\section{REFERENCIAS BIBLIOGRÁFICAS}

Consejo de Defensa del Estado. Mediación por daños en salud Estadísticas 2015. Santiago de Chile, Consejo de Defensa del Estado, 2015. Disponible en: http:// w w w. c d e.cl/w p s/portal/! u t/p/b $1 /$ jZDLCsIwEEW_xS_ITV9pI9NHOIJpEUVtNtKFSKWP jfj9xi KCoLGzGBg4hztcpInDfR8wKxTsyPTY3rtLeumse2ftw5OngPEMSeEgStRiETsSO24ymCAxgC JotwTa0BVUYaCeJoGKB2Qu8zHjyFY_Y14W9 AbSNhgHrv1FQC_sJ8S8Af_8D0 J_L IgxmwVTQDIg6qfBrObNC9IDIqrh6tHjpkPs8!/dl4/d5/ L 2 d J Q S E v U U t 3 Q S 80 S m t F L 1 o 2 X z Q y MDBCQjFBMDg2M0YwSTdDN1RBR1QxR0Uw/

Moscoso, K. \& Smok, P. Responsabilidad sanitaria en odontólogos. Casuística de casos evaluados en el Servicio Médico Legal de Chile. Rev. Med. Chile, 143(3):34551, 2015.

Salinas, J. Descripción de las prestaciones que fueron registradas en el Servicio de Cirugía Bucal del Hospital Clínico San Borja Arriaran, en la Región Metropolitana de Chile el año 2011: Estudio Transversal. Tesina para optar al grado de Cirujano Dentista. Santiago, Universidad de Los Andes, 2012.

Superintendencia de Salud. Estadísticas de Mediación con Prestadores Privados de Salud Ley No 19.966. Período: 10 de Marzo de 2005 al 30 de junio de 2015.Santiago, Gobierno de Chile, Superintendencia de Salud, 2015. Disponible en http://www.supersalud.gob.cl/ documentacion/569/articles-12879_recurso_1.pdf

Dirección para Correspondencia:

Dra. Karla Moscoso Matus

Odontólogo

Auditor Servicio Médico Legal

Santiago

CHILE

Tel: 56-28929245

$56-984281855$

Emai: kmoscoso@gmail.com

Recibido : 27-10-2015

Aceptado: 28-03-2016 